DOI: https://doi.org/10.47405/mjssh.v7i1.1215

\begin{tabular}{|c|c|}
\hline 4.581 & Malaysian Journal of Social Sciences and Humanities (MJSSH) \\
\hline $\begin{array}{l}\text { Malaysian Journal of } \\
\text { socal s ciences and }\end{array}$ & Volume 7, Issue 1, January 2022 \\
\hline (MJ-SSH) & e-ISSN : 2504-8562 \\
\hline & $\begin{array}{l}\text { Journal home page: } \\
\text { www.msocialsciences.com }\end{array}$ \\
\hline
\end{tabular}

\title{
Kesan Modul Terapi Rasional Emotif Tingkah Laku (REBT) Terhadap Sistem Kepercayaan dan Estim Kendiri dalam kalangan Pelatih di Sekolah Tunas Bakti
}

\author{
Asma Mat', Wan Marzuki Wan Jaafar ${ }^{2}$ \\ 1Pusat Kaunseling, Jabatan Hal Ehwal Pelajar, Universiti Utara Malaysia (UUM), Malaysia \\ 2Pengajian Pendidikan, Universiti Putra Malaysia (UPM), Malaysia \\ Correspondence: Asma Bt Mat (m.asma@uum.edu.my)
}

\begin{abstract}
Abstrak
Kepercayaan tidak rasional merupakan kepercayaan yang bersifat rigid dan terlalu ekstrem, tidak logik, tidak konsisten dengan dunia realiti, tidak boleh dibuktikan secara empirikal serta boleh menghalang seseorang individu ke arah pencapaian matlamat. Estim kendiri pula ialah proses perkembangan yang dialami oleh seseorang individu yang akan membawa kepada perubahan daripada orientasi luaran kepada penilaian dalaman. Oleh itu, kajian ini bertujuan untuk mengenal pasti keberkesanan modul terapi Rasional Emotif Tingkah Laku (REBT) terhadap sistem kepercayaan dan estim kendiri dalam kalangan remaja. Sampel dalam kajian ini merupakan pelatih-pelatih dari Sekolah Tunas Bakti Sungai Besi, Kuala Lumpur. Seramai 100 orang pelatih-pelatih yang terdiri daripada mereka yang berumur 15 hingga 20 tahun. Kesemua responden dipilih menggunakan persampelan rawak mudah dan dibahagikan kepada dua kumpulan iaitu kumpulan rawatan $(\mathrm{n}=50)$ yang menerima terapi menggunakan modul REBT dan kumpulan kawalan $(n=50)$ yang menerima terapi tanpa modul REBT. Analisis MANCOVA dijalankan digunakan bagi mengenal pasti perbezaan yang signifikan terhadap skor min kepercayaan tidak rasional dan estem kendiri antara dua kumpulan berkenaan. Berdasarkan hasil kajian yang diperoleh dapat dirumuskan bahawa terapi REBT berkesan diaplikasikan terhadap pelatih-pelatih di Sekolah Tunas Bakti.
\end{abstract}

Kata kunci: kepercayaan, estim kendiri, remaja, Tunas Bakti, REBT

\section{Effect of Rational Emotive Behaviour Therapy on System Belief And Self-Esteem Among Trainees in Sekolah Tunas Bakti}

\begin{abstract}
Irrational beliefs are beliefs that are rigid and too extreme, illogical, inconsistent with the world of reality, cannot be proven empirically and can hinder an individual towards the achievement of goals. Self-esteem, on the other hand, is a developmental process experienced by an individual that will lead to a change from external orientation to internal evaluation. Therefore, this study aimed to identify the effectiveness of the Rational Emotive Behavioral Therapy (REBT) module on belief systems and selfestimation among adolescents. The sample in this study are trainees from Sekolah Tunas Bakti Sungai Besi, Kuala Lumpur. A total of 100 trainees consisting of those aged 15 to 20 years. All respondents were selected using simple random sampling and divided into two groups, namely the treatment group $(\mathrm{n}=50)$ who received therapy using the REBT module and the control group $(\mathrm{n}=50)$ who received therapy without the REBT module. MANCOVA analysis was used to identify significant differences in the mean scores of irrational beliefs and self-esteem between the two groups. Based on the results of
\end{abstract}


Malaysian Journal of Social Sciences and Humanities (MJSSH), Volume 7, Issue 1, (page 50 - 58), 2022

DOI: https://doi.org/10.47405/mjssh.v7i1.1215

the study, it can be concluded that REBT therapy is effective applied to the trainees at Sekolah Tunas Bakti.

Keywords: beliefs, self-esteem, adolescence, Tunas Bakti, REBT

\section{Pengenalan}

Kepercayaan memainkan peranan penting dalam kehidupan manusia yang boleh menunjukkan kebahagiaan dan kegembiraan seseorang. Nalini et al. (2015) kepercayaan boleh dibahagikan kepada kepercayaan yang negatif atau positif serta kepercayaan yang rasional atau tidak rasional. Kajian terdahulu oleh Ellis (1962) telah menyatakan bahawa, manusia mempunyai kecenderungan secara semula jadi untuk berfikiran sama ada secara rasional ataupun tidak rasional. Kepercayaan rasional manusia boleh dibangunkan seawal usia bermula zaman kanak-kanak hingga dewasa supaya individu tersebut boleh diterima oleh orang lain. Kepercayaan yang rasional merupakan kesan daripada pemikiran yang realistik dan fleksibel manakala kepercayaan tidak rasional merupakan sesuatu yang tidak mempunyai sokongan logikal, empirikal dan pragmatik (Ellis, 1970).

Kepercayaan tidak rasional boleh mendorong kepada pemikiran, emosi dan tingkah laku yang memberikan kesan negatif sehingga merosakkan diri serta secara signifikannya boleh mengganggu kehidupan seharian seseorang individu dan juga kebahagiaan orang lain yang berada dalam lingkungan individu terbabit. Koopmas et al. (1994) menterjemahkan bahawa kepercayaan tidak rasional sebagai "proses pemikiran yang tidak realistik yang mana peristiwa tersebut sukar untuk ditafsirkan sehingga menyebabkan individu tersebut mengalami masalah tekanan emosi”. Coon dan Mitterer (2009) dan Davies (2008) menyatakan bahawa kepercayaan tidak rasional berpunca daripada masalah emosi, ketidakfungsian tingkah laku dan kurang penerimaan terhadap estim kendiri. Impak daripada sistem kepercayaan negatif ini juga boleh mendorong seseorang individu untuk terlibat dalam salah laku moral.

Berdasarkan statistik yang dilaporkan OSAC (United States Department of State, Bureau of Diplomatic Security), Malaysia mempunyai kadar jenayah yang tertinggi di Asia Tenggara. Faktor-faktor seperti kekurangan kasih sayang daripada ibu bapa atau keluarga, peranan media massa yang memaparkan pelbagai rancangan dan artikel yang kurang berkualiti yang lebih memfokuskan kepada keseronokan, kurangnya didikan agama dan faktor kemiskinan yang menyebabkan remaja berkenaan terlibat dengan gejala sosial. Untuk mengurangkan jenayah sosial yang dialami pelbagai alternatif telah dicadangkan. Menurut Espira (2013), antara cadangan tersebut ialah mengenal pasti masalah yang dialami oleh remaja tersebut, membuat perancangan atau alternatif, meneroka dan melaksanakan perancangan tersebut, melihat kembali alternatif yang dilaksanakan serta menilai kembali kesan daripada aktiviti yang dilakukan.

Oleh yang demikian, Terapi Rasional Emotif Tingkah Laku atau Rational Emotive Behavour Therapy (REBT) yang diasaskan oleh Albert Ellis (1955) merupakan rawatan yang sesuai untuk mengurangkan ketidakrasionalan bagi remaja bermasalah. Hal ini kerana terapi ini menekankan tiga komponen yang terdiri daripada kognitif, emosi dan tingkah laku. Penekanan tiga komponen ini dalam REBT dijangka dapat memberikan impak yang positif dalam merawat remaja. Selain daripada itu, pendekatan REBT juga boleh membantu remaja berkenaan untuk meningkatkan estim kendiri mereka dalam menghadapi cabaran yang akan datang selanjutnya untuk mencapai matlamat hidup. Berdasarkan senario ini, pembangunan dan pelaksanaan modul REBT remaja di sebuah pusat pemulihan akhlak di Wilayah Persekutuan Kuala Lumpur dijalankan dengan tujuan untuk mengkaji kesannya terhadap sistem kepercayaan dan estim kendiri remaja berkenaan.

\section{Sorotan Literatur}

\section{Aplikasi Terapi Rasional Emotif Tingkah Laku}


Terapi Rasional Emotif Tingkah Laku (REBT) mengandaikan bahawa manusia dilahirkan dengan potensi yang baik dan rasional serta berfikiran tidak rasional dan negatif. Dalam erti kata yang lain, manusia samada remaja atau dewasa mempunyai kecenderungan yang negatif mahupun positif dalam diri mereka. Menurut Albert Ellis (1950), REBT menekankan pemikiran, tingkah laku serta perasaan. Pendekatan terapi ini juga adalah direktif yang menekankan psiko-pendidikan serta pengajaran dalam pemikiran dan perasaan seseorang individu (Corey, 2018).

Golongan remaja merupakan aset Negara yang perlu dibimbing dan dibantu agar mereka dapat menjalani kehidupan yang lebih sihat dalam konteks kognitif, tingkah laku serta emosi dalam kehidupan mereka. Sekiranya aspek berikut diabaikan, kehidupan remaja akan menjadi lebih pasif serta berkemungkinan ada yang memikirkan untuk membunuh diri. Selain daripada itu, terapi REBT juga menekankan antara pemikiran tidak rasional manusia dengan permasalahan emosi manusia, serta menyatakan bahawa manusia mempunyai pilihan sama ada untuk melibatkan diri dengan masalah tersebut atau berhenti untuk terlibat dengan masalah berikut (Aina, 2014).

REBT boleh diaplikasikan dengan jayanya terhadap kanak-kanak dan remaja atau dewasa untuk menangani masalah kemurungan, kebimbangan, kekecewaan, kesempurnaan, gangguan obsesif kompulsif, tekanan (Ellis, 2003), estim kendiri, lokus kawalan (Omizo, 1986), gangguan emosi (Banks, 2006), masalah pembelajaran, dan pencapaian akademik (Ellis \& Wilde, 2002; Hajzler \& Bernard, 1991). Selain itu, pendekatan REBT juga sesuai digunakan untuk mengatasi masalah kemurungan kerana ia menjejaskan keadaan fizikal remaja seperti sakit kepala, sakit dada dan merasa sakit pada seluruh anggota badan (Filani, 1984). Terapi REBT adalah untuk membantu individu menanggani gangguan emosi yang serius berdasarkan tingkah laku yang ditunjukkan dan perasaan yang dialami apabila seseorang itu mempunyai masalah (Knaus, 2001).

Pendekatan REBT juga adalah untuk mengurangkan tahap kemarahan yang melampau, kemurungan dan kebimbangan yang boleh mengganggu keupayaan pelajar untuk mencapai matlamat dengan mengatasi masalah berikut (Bernard, 1990). Menurut (Vernon, 1996) menyatakan bahawa teknik terapi dalam REBT perlu disampaikan secara berstruktur dan teratur untuk meningkatkan kemahiran dan sebagai pengukuhan kepada remaja khusus. Dengan ini, REBT amat sesuai untuk diimplementasikan terhadap para pelatih kerana mereka tergolong dalam kategori remaja yang berumur 12 hingga 20 tahun.

\section{Pembangunan Modul Terapi Rasional Emotif Tingkah Laku (REBT)}

Teori Tingkah Laku Kognitif ini menekankan kepada pemikiran, penilaian, penentuan, penganalisisan serta tindakan klien. Selain daripada itu teori ini juga menyentuh mengenai pandangan bahawa kognitif, emosi dan tingkah laku berinteraksi secara signifikan serta mempunyai hubungan antara sebab dengan akibat sesuatu perkara. Teori kognitif tingkah laku ini berdasarkan andaian bahawa pembentukan yakin pada diri sendiri boleh membentuk tingkah laku seseorang individu.

Menurut Meichenbaum (1977) menyatakan bahawa kerangka Teori Pembelajaran Kognitif boleh mengubah tingkah laku eksplisit seseorang dengan tingkah laku secara terang-terangan. Oleh yang demikian teknik-teknik tingkah laku seperti tingkah laku operan, peniruan dan tingkah laku pengulangan boleh digunakan dalam proses pemikiran serta komunikasi secara individu agar lebih jelas dan lebih subjektif. REBT ialah satu terapi yang berbentuk didaktif, kognitif dan berorientasikan tindakan. Ia menekankan peranan fikiran dan sistem pemikiran sebagai punca masalah peribadi. Manusia cenderung untuk dipengaruhi oleh pemikiran yang salah (faulty) dan hal ini menyebabkan gangguan emosi dan tingkah laku serta pemikiran yang menentukan perasaan dan tindakan individu.

\section{Pembinaan Modul Terapi Rasional Emotif Tingkah Laku}

Modul merupakan bahan pembelajaran yang disusun secara sistematik dan menarik yang merangkumi isi kandungan, kaedah pelaksanaan serta pengajaran daripada aktiviti tersebut supaya pengguna modul mendapat pengajaran yang baik di sebalik modul berikut (Anwar, 2009). Selain itu, ciri-ciri modul yang baik menurut Anwar (2009) ialah pengguna dapat memahaminya dengan jelas ketika membaca 
dan mengaplikasikan modul tersebut (self instructional), bahan atau peralatan yang digunakan dalam modul tersebut lengkap (self contained), modul yang digunakan tidak perlu bergantung kepada modul yang lain (stand alone), modul tersebut haruslah adaptif dan bersesuaian dengan teknologi terkini (adaptif), modul tersebut haruslah mudah untuk digunakan oleh pengguna (user friendly) dan konsisten dari segi tulisan (font), jenis tulisan dan tanda bacaan, (Anwar 2010).

Modul yang dipilih oleh penyelidik dalam kajian ini adalah Modul Terapi Rasional Emosi Tingkah laku yang diadaptasi daripada buku "The REBT Super-Activity Guide: 52 Week of REBT for Client, Groups, Students and You" oleh Garcy (2009) kerana modul ini amat bersesuaian dengan remaja di Pusat Pemulihan Akhlak. Bagi Terapi Rasional Emosi Tingkah Laku mempunyai 15 sesi yang merangkumi 32 aktiviti secara keseluruhannya serta pengenalan dalam sesi kaunseling. Modul tersebut diterjemahkan ke dalam Bahasa Melayu dengan menggunakan ayat-ayat yang mudah difahami oleh pelatih-pelatih di Sekolah Tunas Bakti Sungai Besi, Kuala Lumpur.

Setelah objektif modul ditetapkan, penyelidik membuat terjemahan modul REBT daripada Bahasa Inggeris kepada Bahasa Melayu dengan menggunakan tiga orang pakar bahasa. Menurut Brislin (1976) dalam bukunya "Translation: Applications and Research"menyatakan bahawa penterjemahan merupakan aliran pemikiran dari satu bahasa kepada bahasa yang lain. Kedua, bahasa yang ingin diterjemahkan boleh sama, berlainan bahasa dan bahasa yang sama tetapi digunakan dalam waktu yang berbeza. Selain daripada itu Brislin, Lonner dan Thondike (1973) mencadangkan bahawa panel yang dipilih terdiri daripada tiga orang pakar Bahasa Melayu yang mempunyai pengkhususan dalam Psikologi Kaunseling dan tiga orang pakar dalam Bahasa Inggeris. Panel untuk pakar penterjemahan ini ditentukan oleh penyelidik sendiri berdasarkan kepercayaan dan kebolehan mereka.

Dalam menterjemahkan modul REBT ini penyelidik telah melantik tiga orang pakar dalam Kaunseling yang juga pakar dalam Bahasa Inggeris dan Bahasa Melayu untuk membuat terjemahan tersebut. Seterusnya penyelidik telah meminta tiga orang pakar dalam Bahasa Inggeris untuk menterjemahkan modul REBT tersebut dalam Bahasa Melayu kepada Bahasa Inggeris. Bagi memastikan proses penterjemahan lebih mantap dan menetapi objektif modul, kedua-dua kelompok penterjemah perlu berbincang bersama untuk membuat pengubahsuaian modul tersebut dan memastikan ketepatan istilah yang digunakan selaras dengan konteks asal item dan tepat menurut perspektif kaunseling.

Setelah proses ini selesai, terjemahan tadi diserahkan kepada dua orang pensyarah dalam bidang Bahasa Melayu untuk membuat cadangan serta ulasan bagi ketepatan makna, perkataan dan struktur bahasa pada setiap item yang digunakan supaya adaptasi Modul REBT yang digunakan lebih mudah difahami oleh pelatih-pelatih di Sekolah Tunas Bakti nanti. Tujuan penyelidik membuat terjemahan bahasa kerana majoriti pelatih-pelatih di Sekolah Tunas Bakti mempunyai pendidikan Unit Penilaian Sekolah Rendah (UPSR) dan Penilaian Menengah Rendah (PMR) sahaja.

Akhir sekali penyelidik melaksanakan atau mengaplikasikan modul REBT di Sekolah Tunas Bakti selepas modul tersebut diterima selepas melalui beberapa proses adaptasi penterjemahan Modul REBT. Sebagai kesimpulannya, modul REBT ini sesuai digunakan kerana ia lebih mudah difahami serta aktiviti yang digunakan sangat bersesuaian dengan pelatih-pelatih di Sekolah Tunas Bakti. Selain daripada itu, modul tersebut sangat komprehensif untuk diaplikasikan terhadap pelatih-pelatih di STB khususnya dalam kajian eksperimen asalkan penyelidik mengikuti garis panduan yang telah ditetapkan oleh Garcy (2009).

\section{Kandungan Modul Terapi Rasional Emotif Tingkah Laku (REBT)}

Modul yang dibina ini berasaskan Pendekatan Rational Emotif Tingkah laku (REBT) yang telah diperkenalkan oleh Albert Ellis pada tahun 1955 (Zaharen et al., 2019). Pendekatan ini menekankan aspek kognitif iaitu berorientasikan pemikiran, emosi seseorang individu sehingga mempengaruhi aspek tingkah laku individu berkenaan (Ellis, Shaughnessy \& Mahan, 2003; Wallen, DiGiuseppe \& Dryden, 1992). Modul ini mempunyai pelbagai aktiviti yang telah dirancang secara sistematik dan lebih afektif seperti yang telah ditetapkan dalam objektif serta teori yang telah dikemukakan dalam kajian ini (Rajah 1). 
Malaysian Journal of Social Sciences and Humanities (MJSSH), Volume 7, Issue 1, (page 50 - 58), 2022

DOI: https://doi.org/10.47405/mjssh.v7i1.1215

Rajah 1: Kandungan Modul Terapi Rasional Emotif Tingkah Laku (REBT)

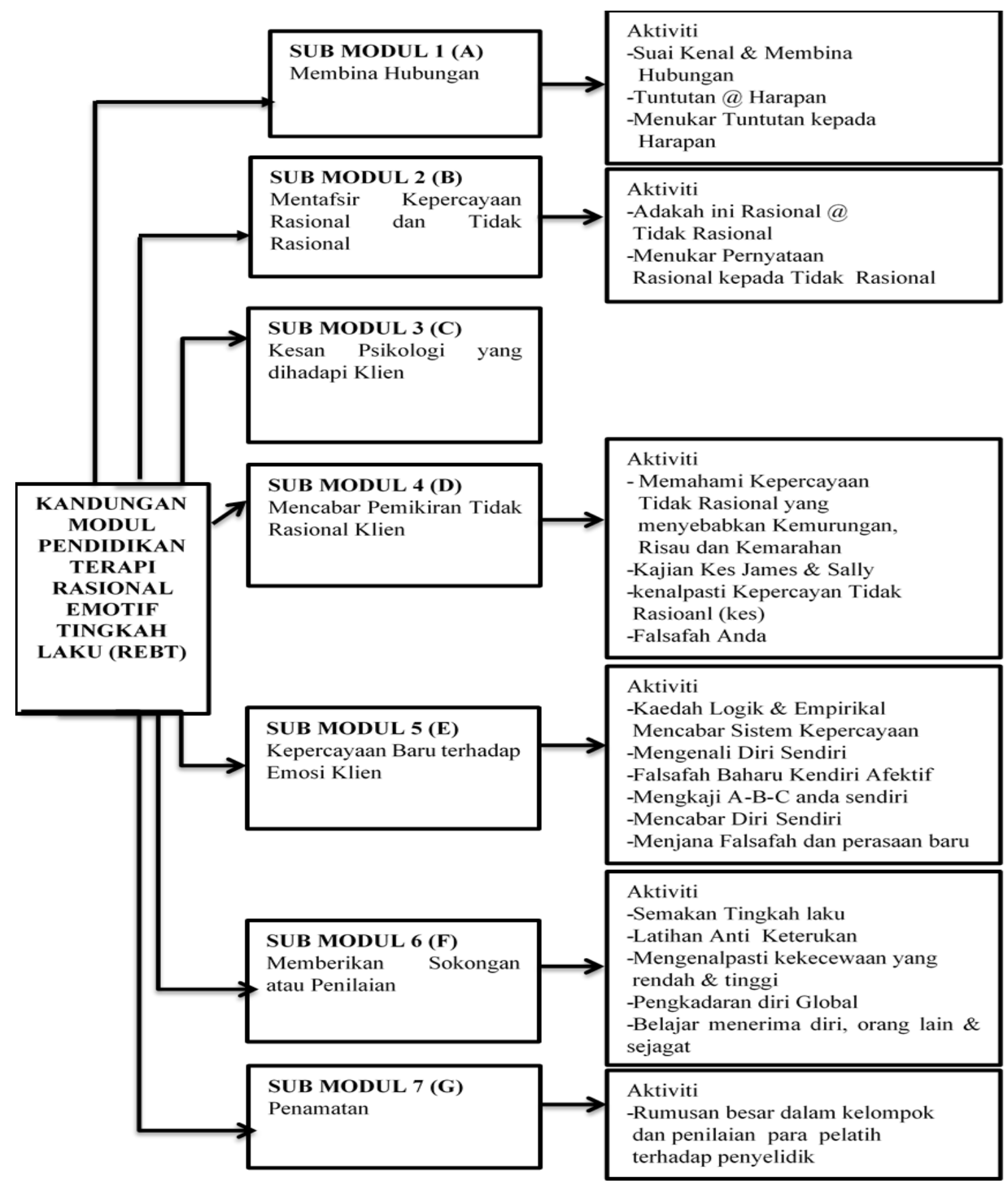

Menurut Md.Noor (2012) modul ini merupakan pembelajaran yang terancang dan berstruktur yang boleh digunakan oleh pengamal-pengamal kaunseling di Malaysia dan individu yang terlibat dengan profesion menolong manusia dalam masyarakat di samping meningkatkan estim kendiri yang tinggi dalam diri individu tersebut. Manakala Gladding (2020) juga mentakrifkan bahawa bimbingan melibatkan pertolongan yang diberikan untuk membantu seseorang individu membuat keputusan ke arah matlamat yang lebih positif supaya memberi impak ke atas perkembangan mental, emosi, tingkah laku, sosial, intelek, fizikal, kejiwaan serta kerohanian dalam diri mereka (Shertzer \& Stone, 1981). Selain itu, ia merupakan satu proses menolong individu untuk memahami masyarakat serta menggunakan keupayaan dan bakat yang ada dalam diri mereka (Abdul Malek, 2004).

Kandungan modul Rasional Emotif Terapi juga mestilah bersesuaian dengan latar belakang pelatihpelatih di STB Sungai Besi, Kuala Lumpur kerana ia perlu diubahsuai supaya modul tersebut lebih mudah difahami, padat, jelas dan boleh menarik minat mereka. Selain itu, modul ini juga terdiri 
daripada latihan dalam kumpulan (LDK), main peranan (role play) atau melakonkan sesuatu watak, melukis serta memerlukan perbincangan di akhir setiap aktiviti supaya para pelatih lebih memahami untuk diaplikasikan dalam diri mereka. Aktiviti-aktiviti yang disediakan berobjektifkan motivasi agar mereka lebih yakin untuk berjaya setelah dibebaskan daripada STB nanti.

Selain daripada itu terdapat juga aktiviti yang direka sendiri oleh pengkaji seperti suai kenal, membina hubungan, rasional atau tidak rasional, emosi sihat vs emosi tidak sihat, belajar A-B-C, memahami kepercayaan tidak rasional yang menyebabkan kemurungan dan sebagainya. Penyelidik juga menyediakan lembaran kerja sebagai nota untuk para pelatih supaya mereka lebih memahaminya. Manakala bagi pelatih-pelatih yang tidak dapat membaca, mereka dibantu oleh ahli dalam kelompok tersebut di samping penyelidik sendiri yang memberikan bantuan ketika melaksanakan aktiviti bersama mereka.

Secara keseluruhannya, aktiviti ini adalah berkonsepkan asas terhadap REBT agar pelatih-pelatih lebih berfikiran rasional berbanding sebelum ini. Menurut kajian yang telah dilakukan oleh Zaharen et al. (2019) terdapat beberapa sub modul yang boleh digunakan berasaskan konsep Terapi Rasional Emotif Tingkah Laku seperti di Rajah 1.

\section{Metod Kajian}

Reka bentuk kajian yang digunakan oleh pengkaji dalam kajian ini ialah melalui reka bentuk eksperimen tulen (true experimental design) yang menggunakan pendekatan kuantitatif untuk mencapai objektif kajian. Kajian eksperimen digunakan untuk mengetahui keberkesanan terapi REBT terhadap sistem kepercayaan, kemurungan dan estim kendiri remaja di Pusat Pemulihan Akhlak khususnya di Sekolah Tunas Bakti Sungai Besi, Kuala Lumpur. Justeru itu, reka bentuk kajian yang digunakan oleh penyelidik ialah kajian eksperimen yang merangkuni ujian-pra (pre-test), ujian-pasca (post-test) dan ujian-susulan (followup-test) bagi melihat perbezaan dalam setiap hasil yang diperolehi.

Dalam kajian ini, pengkaji hanya memilih 100 orang responden dengan menggunakan persampelan rawak mudah (sample random sampling) yang mana setiap pelatih dalam kumpulan tersebut mempunyai peluang yang sama untuk dipilih sebagai sampel (Norliza, 2012). Pelatih-pelatih yang dipilih sebagai sampel dimasukkan ke dalam kumpulan rawatan dan kumpulan kawalan (control group) yang mana pelatih-pelatih berkenaan berumur antara 15 hingga 20 tahun sahaja dan kumpulan rawatan mempunyai 50 orang pelatih serta kumpulan kawalan juga mempunyai 50 pelatih. Ini adalah kerana reka bentuk eksperimen tulen (true experimental design) telah dilakukan oleh penyelidik dengan memilih reka bentuk kumpulan kawalan ujian-pra, ujian-pasca dan ujian-susulan yang melibatkan sekurang-kurangnya dua kumpulan yang diagihkan secara rawak (Noraini Ahmad, 2010).

\section{Hasil Kajian}

\section{Demografi Responden}

Data yang diperoleh dianalisis menggunakan perisian IBM Statistical Package for Social Sciences (SPSS) versi 25.0. Jadual 1 menunjukkan profil responden kajian. Bagi kumpulan kawalan seramai 17 orang (34\%) pelatih berumur 15 tahun, 21 pelatih (42\%) berumur 16 tahun, 9 pelatih (18\%) berumur 17 tahun, 2 pelatih (4\%) berumur 19 tahun dan seorang pelatih (2\%) berumur 20 tahun. Bagi kumpulan rawatan pula, seramai 7 pelatih (14\%) berumur 15 tahun, 31 pelatih (62\%) berumur 16 tahun dan 12 pelatih (24\%) berumur 17 tahun. Bagi kategori bangsa dalam kumpulan kawalan, seramai 49 pelatih (98\%) adalah berbangsa Melayu dan seorang pelatih (2\%) berbangsa India manakala bagi kumpulan rawatan pula, seramai 43 pelatih (86\%) berbangsa Melayu, 4 pelatih (8\%) berbangsa Cina dan 3 pelatih $(6 \%)$ berbangsa India. Bagi tahap pendidikan dalam kumpulan kawalan, seramai 26 pelatih $(52 \%)$ mempunyai UPSR, 22 pelatih (44\%) mempunyai PMR/PT3/SPM dan 2 pelatih (4\%) mempunyai STPM, manakala bagi kumpulan rawatan, seramai 21 pelatih (42\%) mempunyai UPSR, 22 pelatih (44\%) mempunyai PMR/PT3/SPM dan 7 pelatih (14\%) mempunyai STPM. 
DOI: https://doi.org/10.47405/mjssh.v7i1.1215

Jadual 1: Profil Responden Kajian

\begin{tabular}{llcccc}
\hline Profil & & \multicolumn{2}{c}{ Kawalan $(\mathbf{n}=\mathbf{5 0})$} & \multicolumn{2}{c}{ Rawatan $(\mathbf{n = 5 0})$} \\
\cline { 3 - 6 } & & $\mathbf{n}$ & $\mathbf{\%}$ & $\mathbf{n}$ & $\mathbf{\%}$ \\
\hline Umur & 15 & 17 & 34 & 7 & 14 \\
& 16 & 21 & 42 & 31 & 62 \\
& 17 & 9 & 18 & 12 & 24 \\
& 18 & 0 & 0 & 0 & 0 \\
Bangsa & 19 & 2 & 4 & 0 & 0 \\
& 20 & 1 & 2 & 0 & 0 \\
\multirow{5}{*}{ Tahap Pendidikan } & 49 & 98 & 43 & 86 \\
& Melayu & 0 & 0 & 4 & 8 \\
& Cina & 1 & 2 & 3 & 6 \\
& India & 26 & 52 & 21 & 42 \\
& UPSR & 22 & 44 & 22 & 44 \\
& PMR/PT3/SPM & 2 & 4 & 7 & 14 \\
\hline
\end{tabular}

\section{Keberkesanan intervensi}

Analisis multivariat kovarians (MANCOVA) dijalankan untuk melihat perbezaan skor min kepercayaan tidak rasional dan estem kendiri bagi dua kumpulan pelatih iaitu kumpulan kawalan dan rawatan. Berdasarkan Jadual 2, didapati bahawa kesan kumpulan menunjukkan terdapat perbezaan skor kepercayaan yang signifikan antara pelatih kumpulan kawalan dan rawatan $\left(F=60.074, p<0.05, \eta_{\mathrm{p}}{ }^{2}=\right.$ 0.558). Manakala kesan masa menunjukkan tidak terdapat perbezaan skor yang signifikan antara masa pascaujian dengan ujian lanjutan $\left(F=1.343, p>0.05, \eta_{p}{ }^{2}=0.028\right)$. Kesan interaksi antara masa dan kumpulan pula menunjukkan perbezaan skor yang signifikan $\left(F=58.855, \mathrm{p}<0.05, \eta_{\mathrm{p}}{ }^{2}=0.553\right)$.

Jadual 2: Analisis MANCOVA Pengukuran Berulang dengan Praujian sebagai Kovariat

\begin{tabular}{lcccccc}
\hline Kesan & $\begin{array}{c}\text { Wilks' } \\
\text { Lambda }\end{array}$ & $\boldsymbol{F}$ & dk1 & dk2 & Nilai p & ${\text { Partial- } \boldsymbol{\eta}^{\mathbf{2}}}$ \\
\hline Kumpulan & 0.442 & 60.074 & 2 & 95 & $\mathbf{0 . 0 0 0}$ & 0.558 \\
Masa & 0.972 & 1.343 & 2 & 95 & 0.266 & 0.028 \\
Masa*Kumpulan & 0.447 & 58.855 & 2 & 95 & $\mathbf{0 . 0 0 0}$ & 0.553 \\
\hline
\end{tabular}

$* * \mathrm{p} \leq .05$

Keputusan ujian dalam subjek (lihat Jadual 3) menunjukkan kesan utama masa ujian tidak signifikan pada aras p $>0.05$ terhadap kedua-dua pemboleh ubah iaitu kepercayaan tidak rasional $\mathrm{F}(1,97)=0.248$, $\mathrm{p}=0.620$ dan estem kendiri $\mathrm{F}(1,97)=2.497, \mathrm{p}=0.117$. Manakala kesan interaksi antara masa dan kumpulan pula menunjukkan kesan interaksi yang signifikan bagi estem kendiri $\mathrm{F}(1,97)=115.864, \mathrm{p}=$ 0.000 ; dengan saiz kesan yang besar (partial eta squared $=0.547$ ).

Jadual 3: Ujian dalam subjek (test within subject) bagi kepercayaan tidak rasional dan estem kendiri

\begin{tabular}{|c|c|c|c|c|c|c|c|}
\hline Kesan & Pembolehubah & $\begin{array}{c}\text { Jumlah } \\
\text { kuasa dua }\end{array}$ & dk & $\begin{array}{c}\text { Min } \\
\text { kuasa dua }\end{array}$ & $\mathbf{F}$ & Nilai $p$ & Partial- $\eta^{2}$ \\
\hline \multirow[t]{2}{*}{ Masa } & $\begin{array}{l}\text { Kepercayaan tidak } \\
\text { rasional }\end{array}$ & 0.008 & 1 & 0.008 & 0.248 & 0.620 & 0.003 \\
\hline & Estem kendiri & 1.310 & 1 & 1.310 & 2.497 & 0.117 & 0.025 \\
\hline \multirow[t]{2}{*}{$\begin{array}{l}\text { Masa* } \\
\text { Kumpulan }\end{array}$} & $\begin{array}{l}\text { Kepercayaan tidak } \\
\text { rasional }\end{array}$ & 0.123 & 1 & 0.123 & 3.887 & 0.052 & 0.039 \\
\hline & Estem kendiri & 60.804 & 1 & 60.804 & 115.864 & 0.000 & 0.547 \\
\hline
\end{tabular}

$* * \mathrm{p} \leq .05$ 
Rajah 2: Min margin jangkaan estem kendiri kumpulan kawalan dan rawatan

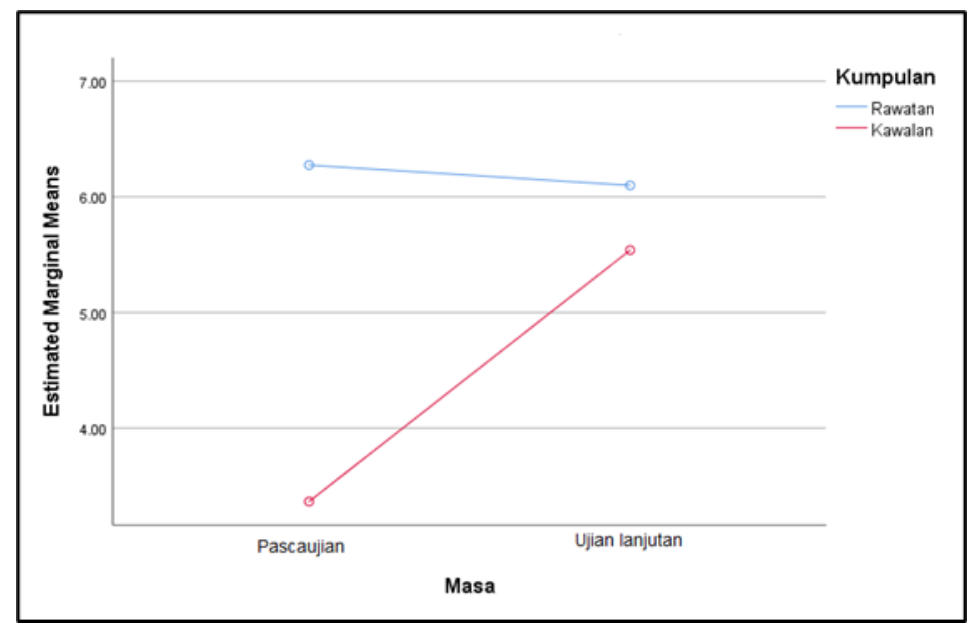

Rajah 2 menunjukkan ujian-pasca berbanding ujian-susulan menunjukkan kumpulan yang menggunakan Terapi Rasional Emosi Tingkah Laku hanya sedikit berbeza nilai skor min estem kendiri pelatih. Manakala bagi kumpulan kawalan, nilai skor min estim kendiri menunjukkan peningkatan yang ketara. Namun demikian kedua-dua kumpulan ini menunjukkan peningkatan nilai estem kendiri berbanding semasa pra-ujian. Oleh itu, dapat dijelaskan bahawa tahap estim kendiri pelatih masih boleh meningkat walaupun tanpa menggunakan modul Terapi Rasional Emosi Tingkah Laku kerana pelatih sudah sedia mempunyai estim kendiri yang tinggi serta kesedaran untuk menjadi manusia berguna untuk agama, bangsa dan negara. Selain itu, para pelatih juga mempunyai pemikiran yang positif kerana sering mengikuti aktiviti-aktiviti yang ditetapkan di Sekolah Tunas Bakti seperti aktiviti kaunseling, keagamaan dan kemahiran hidup.

\section{Kesimpulan}

Secara kesimpulannya, kajian ini bertujuan untuk melihat keberkesanan terapi REBT terhadap sistem kepercayaan dan estim kendiri pelatih-pelatih di Sekolah Tunas Bakti Sungai Besi, Kuala Lumpur. Hasil kajian telah diperoleh dianalisis dengan menggunakan statistik deskriptif bagi demografi responden seperti umur, bangsa, taraf pendidikan bertujuan untuk mengetahui nilai kekerapan dan peratusan. Hasil analisis menunjukkan terapi REBT dapat mengurangkan sistem kepercayaan tidak rasional dalam kalangan pelatih. Selain daripada itu terapi REBT dapat meningkatkan tahap estim kendiri. Berdasarkan hasil kajian yang diperoleh dapat dirumuskan bahawa terapi REBT berupaya untuk diaplikasikan terhadap pelatih-pelatih di Sekolah Tunas Bakti berkenaan dalam kelompok kecil. Dalam kajian ini terdapat beberapa limitasi kajian dari segi jenis responden yang digunakan lokasi kajian. Untuk kajian lanjutan dicadangkan kajian ini dilakukan terhadap Sekolah Tunas Bakti Perempuan dan tidak tertumpu hanya untuk pelatih-pelatih lelaki sahaja. Ini adalah kerana modul Terapi Rasional Emotif Tingkah Laku telah diubahsuai dan sesuai diaplikasikan untuk pelatih-pelatih perempuan di Sekolah Tunas Bakti berkenaan. Walau bagaimanapun responden yang terlibat dalam penyelidikan perlu mempunyai ciri-ciri dan latar belakang yang sama dengan responden yang terlibat dalam penyelidikan ini. Selain daripada itu, kajian keberkesanan terapi REBT tidak tertumpu untuk remaja di Pusat Pemulihan Akhlak sahaja malah ia boleh juga diaplikasikan di penjara, sekolah, sektor kerajaan atau swasta dan di IPT. Terapi REBT ini juga boleh dilakukan terhadap pegawai-pegawai di Pusat Pemulihan akhlak untuk melihat keberkesanannya. Modul yang digunakan juga perlu diubah suai sekiranya diaplikasikan terhadap golongan remaja kanak-kanak dan dewasa agar mudah difahami dan lebih menarik. 


\section{Rujukan}

Abdul Malek Abdul Rahman. (2004). Kesan kaunseling kelompok tingkah laku kognitif dalam merawat tingkah laku langsang buli dikalangan pelajar sekolah menengah. Tesis Doktor Falsafah yang tidak diterbitkan. Universiti Kebangsaan Malaysia, Selangor, Malaysia.

Aina Razlin Mohammad Roose. (2014). Kenali REBT semudah ABC: teori \& konsep asas terapi rasional emotif tingkah laku. Sarawak: Penerbit UNIMAS.

Anuar Ahmad. (2009). Pendidikan moral pelajar terpinggir. Utusan Malaysia, 28 Jun: 2009.

Banks, T.I. (2006). Teaching rational emotive behavior therapy to adolescents in an alternative urban educational setting. Unpublished Doctoral dissertation. Kent State University.

Bernard, R. M. (1990). Using extended captions to improve learning from instructional illustrations. British Journal of Educational Technology, 21(3).

Brislin, R. W. (1976). Comparative research methodology: Cross-cultural studies. International Journal of Psychology, 11(3), 215-229.

Coon, D., \& Mitterer, J. O. (2009). Introduction to Psychology : Gateways to Mind and Behavior (12th ed). United State: Cengage Learning.

Corey, G. (2018). Theory and practice of counseling and psychotherapy (10 ${ }^{\text {th }}$ Ed.). United States: CENGAGE Learning Custom Publishing.

Davies, G. (2008). Employer branding and its influence on managers. European Journal of Marketing, $42(5 / 6), 667-681$.

Ellis, A. (1962). Reason and Emotion in Psychotherapy. New York: Lyle Stuart.

Ellis, A. (1970). The cognitive element in experiential and relationship psychotherapy. Existential Psychiatry, 7(28), 35-52.

Ellis, A. (2003). Reasons why rational emotive behavior therapy is relatively neglected in the professional and scientific literature. Journal of Rational-Emotive \& Cognitive-Behavior Therapy, 21(3-4), 245-252.

Garcy, P.D. (2009). The REBT Super-Activity Guide: 52 Weeks of REBT For Clients, Groups, Students, and YOU! North Charleston SC, United States: Createspace Independent Publishing Platform.

Gladding. S. T. (2020). Groups: A counseling specialty ( $8^{\text {th }}$ Ed.). United States: Pearson Shertzer, B., \& Stone, S. C. (1981). Fundamentals of Guidance (4th ed.). Boston, MA: Houghton Mifflin.

Hajzler, D. J., \& Bernard, M. E. (1991). A review of rational-emotive education outcome studies. School Psychology Quarterly, 6(1), 27-49.

Koopmans, P. C., Sanderman, R., Timmerman, I., \& Emmelkamp, P. M. G. (1994). The Irrational Beliefs Inventory (IBI): Development and psychometric evaluation. European Journal of Psychological Assessment, 10(1), 15-27.

Mohd Zaharen Md Zahir, Md Noor Saper, \& Mohammad Nasir Bistamam. (2019). Kesahan dan kebolehpercayaan modul kelompok bimbingan integrasi REBT-Tazkiyah An-Nafs. Journal of Research, Policy \& Practice of Teachers \& Teacher Education, 9 (1), 58-69.

Norliza Hj Brahim. (2012). Kesediaan Guru Melaksanakan Pembelajaran Berasaskan Projek di Sekolah. Universiti Putra Malaysia, Serdang. Tidak diterbitkan.

Omizo, M. M., Lo, F-L. G., \& Williams, R. E. (1986). Rational-emotive education, self-concept, and locus of control among learning-disabled students. The Journal of Humanistic Education and Development, 25 (2).

Walen, S., DiGiuseppe, R., \& Dryden, W. (1992). A practitioner's guide to rational emotive therapy. New York: Oxford Press. 